\title{
Study on Mechanical Performance of Prestressed UHPFRC U-Beam Bridges
}

\author{
Mengying Liu $\left(\mathbb{D},{ }^{1}\right.$ Eugen Brühwiler $\mathbb{D D}^{2}$ Fengkun Cui $\mathbb{D}^{3},{ }^{3}$ and Yue Xu ${ }^{4}{ }^{4}$ \\ ${ }^{1}$ School of Civil Enginering and Architecture, Linyi University, Linyi 276000, China \\ ${ }^{2}$ Laboratory of Maintenance and Safety of Structures (MCS-ENAC), EPFL-Swiss Federal Institute of Technology Lausanne, \\ Station 18, CH-1015 Lausanne, Switzerland \\ ${ }^{3}$ Department of Civil Engineering, Shandong Jiaotong University, Jinan 250357, China \\ ${ }^{4}$ Highway School, Chang'an University, Xi'an 710064, China
}

Correspondence should be addressed to Mengying Liu; liumengying@lyu.edu.cn

Received 17 November 2020; Revised 8 February 2021; Accepted 1 March 2021; Published 16 April 2021

Academic Editor: Loke Foong

Copyright (C) 2021 Mengying Liu et al. This is an open access article distributed under the Creative Commons Attribution License, which permits unrestricted use, distribution, and reproduction in any medium, provided the original work is properly cited.

The forms of U-shaped UHPFRC beams have not been investigated for the highway footbridge. Compared with the traditional section forms, the U-shaped UHPFRC beams can reduce the material consumption under the condition of providing the same bearing capacity. Furthermore, prestressed U-shaped UHPFRC beams are rarely reported in the existing research. This paper explores the flexural behavior of prestressed ultrahigh-performance fiber-reinforced concrete (UHPFRC) beam bridge having unique design and the material properties of prestressed reinforcement combined with UHPFRC. Based on the unique shape of the U beam, the flexural performance test of the full-scale model of the prestressed UHPFRC U beam is conducted. Then, the finite element model considering material nonlinearity and structural ductility is established using Midas FEA software. Finally, the failure mode, failure process, cracking moment, ultimate moment, and strain of the full-scale model are studied. The calculation formulas of the flexural capacity of UHPFRC $U$ beam considering ductile failure are derived. The comparative analysis results show that the prestressed UHPFRC U beam has an excellent flexural performance. The bending failure of a U-shaped beam belongs to the group of ductile failures, which is characterized by the main crack along the central rib and the loading center, which is accompanied by multiple microcracks. The failure process can be divided into four stages: linear deformation, microcracks development, main cracks development, and bearing capacity decline. The incorporation of steel fiber and the interaction between UHPFRC and reinforcement can effectively reduce the development of cracks. The U-beam bending moment is $50-55 \%$ of the ultimate bending moment. In the UHPFRC bridge design, the deformation can be used as a control index, and material advantages of the UHPFRC can be used to a certain extent. The strain-hardening characteristics of the UHPFRC are obvious in the loading process. The finite element analysis results show that the maximum strain value appears at the central rib, followed by the transverse strain value of the bottom plate, while the minimum strain is the longitudinal strain value of the bottom plate. The deformation of the rib plate is the largest, and the strain of the other measuring points changes slowly. The farther away from the center the measurement point is, the slower its strain changes. Therefore, the load is mainly caused by the central rib and the loading center plate. With the increase in the deformation, the load on both sides continuously moves to the central rib along the plate surface. This study can provide a useful reference for theoretical analysis and design of prestressed U-UHPFRC bridges.

\section{Introduction}

Ultrahigh-performance fiber-reinforced concrete (UHPFRC) is a cement matrix composite material based on the principle of maximum compactness. In recent years, the UHPFRC has gained popularity in the construction and rehabilitation of infrastructures due to its high compressive, pre- and postracking tensile strengths, as well as negligible permeability $[1-3]$. As a new trend in the bridge engineering material field, the UHPFRC application to the prestressed bridge structure can not only provide effective prestress in the beam but also solve the problems of prestressed bridge main span deflection 
and beam cracking, realize structural form diversification and lightweight and thin-walled structure, prolong the service life of the structure, and save resources [4-6]. The UHPFRC bridge structure is convenient for construction and maintenance since the structure has a low life-cycle cost and conforms to the development concepts of low-carbon environmental protection, aesthetics, and economy of modern bridges, thus ensuring technical and economic benefits, great popularization, and high application value [7-9]. Since the superhigh strength and durability of UHPFRC can extend the service life and reduce the maintenance cost of bridges, which could solve many technical problems of conventional bridges, it has still been in its infancy. If prestressed UHPFRC bridges can be popularized, it could provide a great opportunity in the context of green, industrialization, and standardization of the transportation industry $[10,11]$.

The structural behavior of UHPFRC elements has been investigated in a few studies. Several analytical models to predict the failure mode and resistance of composite beams have been developed. The tensile behavior of UHPFRC followed by the results of a large experimental study on a series of composite beams and slabs was presented in [12-14]. Sharif et al. conducted experimental research on adopting UHPC board in the negative moment zone, which improved the thickness of the UHPC board and partial shear connection performance [15]. Deng et al. proposed a type of fully prefabricated beam-column node by using the UHPC node and conducted a numerical analysis of the beam-column connection [16]. Pribramsky and Kopálová used the prefabricated UHPC web to establish a box section combination system and analyzed the mechanical performance [17]. Gurusideswar et al. designed five different UHPC compositions for improving the mechanical properties of conventional control concrete [18]. Fan et al. concluded that the steel fiber with a volume content of up to $3 \%$ would not lead to corrosion of steel rebar and could be safely used in UHPC [19]. Wang et al. studied the strengthening effects of constraints on the UHPC axial compression strength and the reduction effect of annular stress on the axial compression strength of circular steel tubes [20]. Xiujiang et al. investigated experimentally the biaxial flexural fatigue behavior of thin slab elements made of the strain-hardening UHPFRC by means of the ring-on-ring test method [21-23]. The flexural performance of large-scale steel-UHPC composite beams composed of a precast UHPC slab, which was connected to the steel girder by large-headed stud clusters embedded with shear pockets, was studied in [24]. The experimental and numerical study on the dynamic behavior of axially loaded UHPC columns under the low-velocity impact loading was conducted in [25]. Interfaces between the UHPC and NSC were experimentally tested by a common test method for measuring the shear behavior of interfaces [26]. Application of UHPFRC to the specific zones of structural members subjected to severe mechanical and environmental actions has been proven to be an effective method for improving the structural parameters with respect to resistance and durability [7, 24, 27, 28].

In recent years, UHPFRC has been widely used for bridge reinforcement and in deck pavements, but the research on using the UHPFRC material for the whole bridge, as well as the addition of prestressed reinforcement, has still been less [29-31]. However, to explore the structural performances of UHPFRC bridges, better understanding and prediction of material properties are necessary [32-34]. Therefore, in this paper, the failure test of a full-scale prestressed UHPFRC U-shaped beam is conducted, and a nonlinear numerical model is established. Also, the yield line theory is used for the computational model, and results are compared and analyzed to evaluate the mechanical mechanism of the unique type of prestressed UHPFRC U-shaped beam. The results presented in this paper are of great significance for improving the project quality, speeding up the construction process, reducing the project cost, and realizing civilized construction of UHPFRC girder bridges and also provide a useful reference for the design of UHPFRC girder bridges and the formulation of relevant codes.

\section{Full-Scale Model Test of Prestressed UHPFRC U Beam}

2.1. Model Design and Production. The test model was a prestressed UHPFRC U beam full-scale model of the Martinet Bridge in Switzerland, and the whole model was made by casting the UHPFRC with a steel fiber volume rate of $3 \%$. During the design, in order to make the U-beam web artistic, the material consumption and self-weight were reduced, the web height on both sides was different, and there should be many hollow parts in the high web. The low web was a solid structure, as shown in Figure 1(a). It was stipulated that the longitudinal direction of the bridge was the longitudinal direction of the test component, and the transverse direction was the transverse direction of the component. The transverse width of the member was $2879 \mathrm{~mm}$, the height was $1523 \mathrm{~mm}$, and the width of the bottom plate was $2500 \mathrm{~mm}$. Six prestressed steel strands with a nominal diameter of $15.2 \mathrm{~mm}$ were arranged symmetrically at both ends along the longitudinal direction. The cross-section was symmetrical along the transverse axis; the width was $1884 \mathrm{~mm}$, the rib plate thickness was $100 \mathrm{~mm}$, and the ordinary reinforcement with a diameter of $14 \mathrm{~mm}$ was provided; the rest of the plate thickness was $50 \mathrm{~mm}$, as shown in Figures 1(b) and 1(c).

2.2. Model Test Loading and Measurement Scheme. Due to the large size of the test model and the symmetry of the $U$ beam, two jacks with the maximum loading value of $200 \mathrm{kN}$ were selected to be loaded in a concentrated manner along the transverse central axis. The loading position was in each $1 / 2$ bottom plate center, and the loading amount was controlled by the gravity sensor. At the same time, nine displacement sensors and nine strain gauges were arranged to collect the measurement data to track the deformation development and changing process of the component in the bending process. Four strain gauges were arranged along the transverse and longitudinal directions at the bottom center of the $1 / 2 \mathrm{U}$ beam on one side, and five strain gauges were arranged along the center rib. The measuring point No. 3 


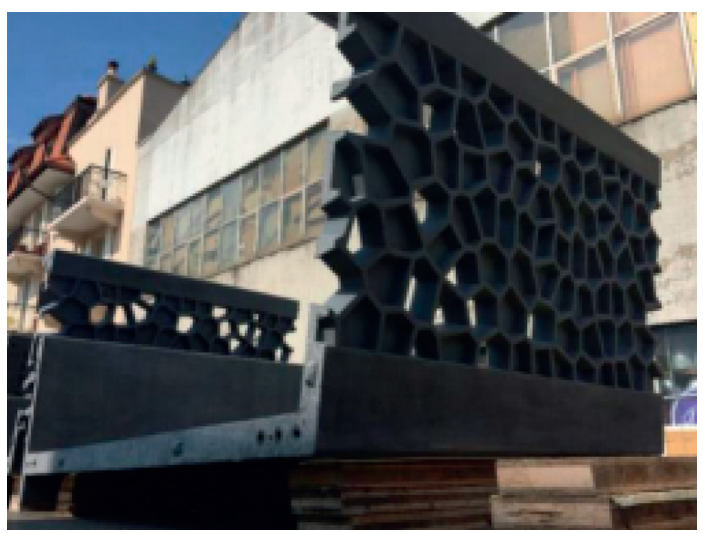

(a)

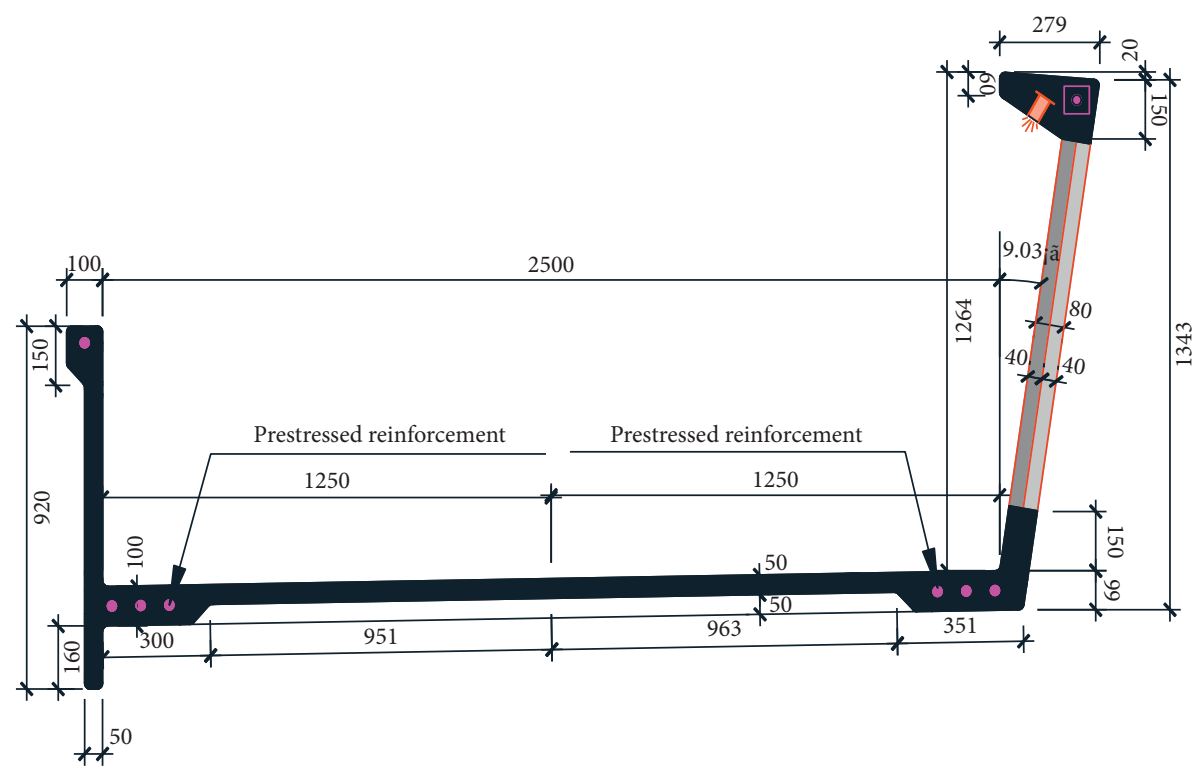

(b)

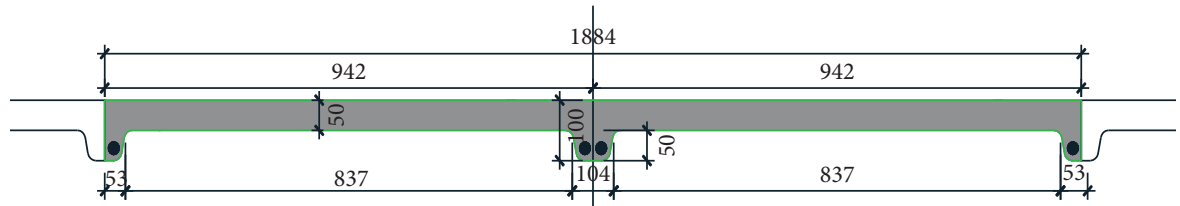

(c)

FIgURE 1: Full-scale model construction of the U beam. (a) Test component of U beam. (b) Cross-section (unit: mm). (c) Longitudinal section (unit: $\mathrm{mm}$ ).

was located in the rib center, and the other four measuring points were symmetrically arranged along the rib; measuring points No. 1 and No. 2 were located on the low web, and measuring points No. 4 and No. 5 were on the high web, as shown in Figure 2(c).

Five displacement sensors were arranged at the bottom, of which two displacement sensors were arranged at the bottom center of each $1 / 2 \mathrm{U}$-beam plate. The remaining three sensors were arranged as follows: one sensor was arranged in the center of the bottom, and the other two sensors were arranged symmetrically at the rib four points. The remaining four sensors were arranged on the top of the bottom plate to measure the displacement of the supports at both ends of the component. The displacement sensors No. 1 and No. 3 were located at the bottom plate of the $1 / 2 \mathrm{U}$ beam, where Force 1 was located. The displacement sensors No. 2 and No. 4 were located at the place where Force 2 was located. The displacement sensors No. 1 and No. 2 were on the high-web side, and displacement sensors No. 3 and No. 4 were on the low-web side. The specific positions and numbers of measuring points are shown in Figure 2.

2.3. Load Step. The full-scale model test was conducted in the Key Laboratory for structural safety maintenance (MCS) of the Federal Polytechnic University of Lausanne (EPFL), 


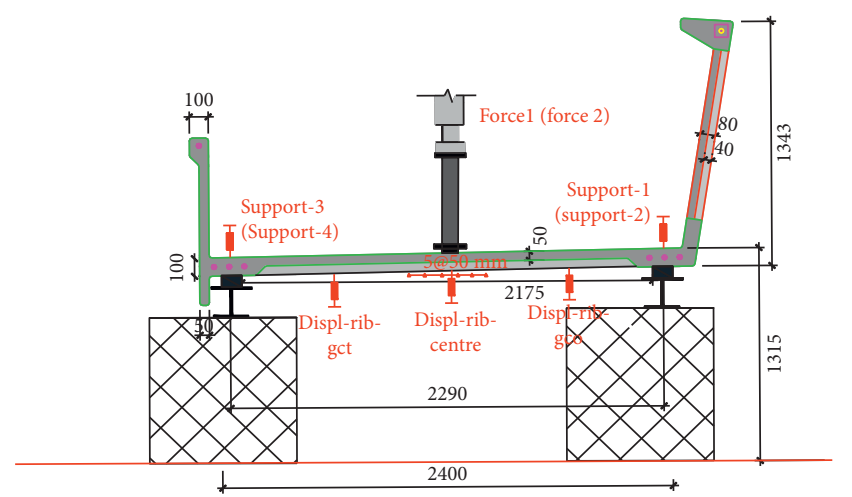

(a)

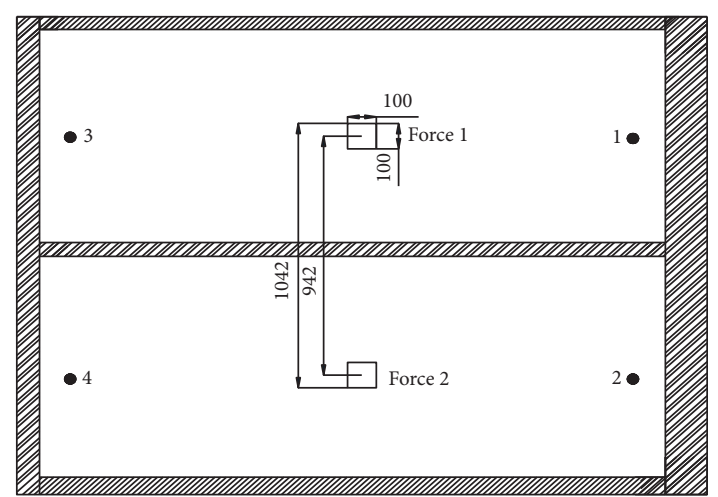

(b)

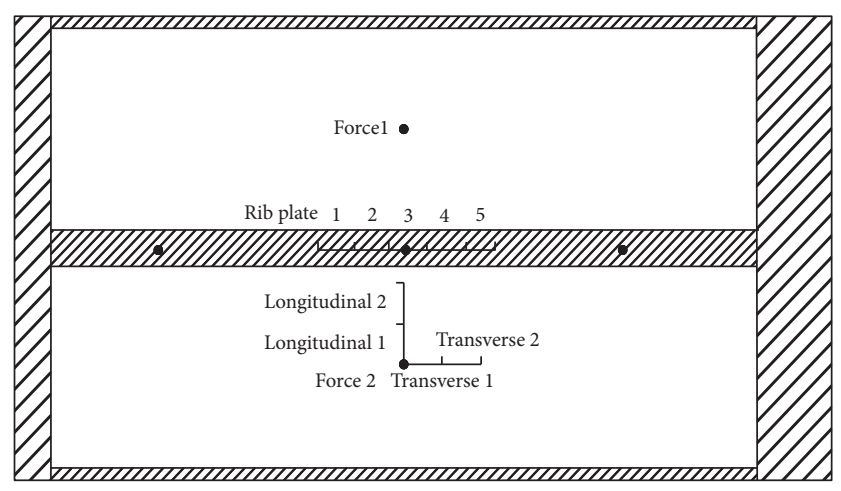

(c)

Figure 2: Positions of measuring points (unit: mm). (a) Test model elevation. (b) Test mode surface. (c) Test mode base.

Switzerland. The U-component test model was placed between two supporting steel beams, and the strip wood blocks were placed between the steel beams and the test model. The loading and measuring devices were installed. Hollow steel columns and steel cushion blocks were used as loading blocks. The loading process started from the initial stage and lasted until the failure occurred. Deformation, strain, and a load of each measuring point were monitored in real time. Crack development and failure mode of the component were also observed in real time. The actual measurement and loading processes are shown in Figure 3.

In the test process, the loading value of each loading point in each stage was chosen according to the theoretical analysis, and the loading values are shown in Table 1 . According to the one-way slab calculation of ultimate bearing capacity, the load was controlled to $20 \mathrm{kN}$ by force and increased until $60 \mathrm{kN}$ of the two-way slab calculation. Then, we change to displacement controlled loading; when the displacement was controlled to $80 \mathrm{~mm}$, the deformation of the rib plate was observed by unloading. According to the structural deformations, the bearing capacity of the rib plate increased, so the load continued to be applied until the component was damaged.

\section{Nonlinear Numerical Analysis}

3.1. Finite Element Model Establishment. In order to verify the correctness of the nonlinear numerical model, the experimental results were compared with the theoretical results, and the numerical model was established using the Midas FEA software for nonlinear analysis. Only the main U-beam stressed part, namely, the bottom plate, was established without considering the asymmetric simulation webs. Because the longitudinal section of the bottom plate was symmetric along the transverse central axis, only half of the $U$ beam was established for analysis. The solid element was used to simulate the U-beam bottom plate, the hexahedron-based grid division method was adopted, and the UHPFRC part was divided into 21,126 elements, having 16,392 nodes. The bar element was used to simulate the prestressed steel tendon and ordinary steel bars, and the reinforced part was divided into 392 elements, having 208 nodes. The finite element model of the member is shown in Figure 4.

3.2. Material Constitutive Model. In order to simulate the nonlinear material performance of the UHPFRC and reinforcement accurately, material characteristics were customized, and the constitutive relation of the UHPFRC was based on the test results. The UHPFRC constitutive model in the finite element analysis adopted the total strain fracture model, in which the compression characteristic function was the Thorenfeldt function, and the tensile characteristic satisfied the multiline function, as shown in Figure 5. The Von Mises model was used to simulate the prestressed and ordinary steels. Specific material characteristics parameters are given in Table 2. 


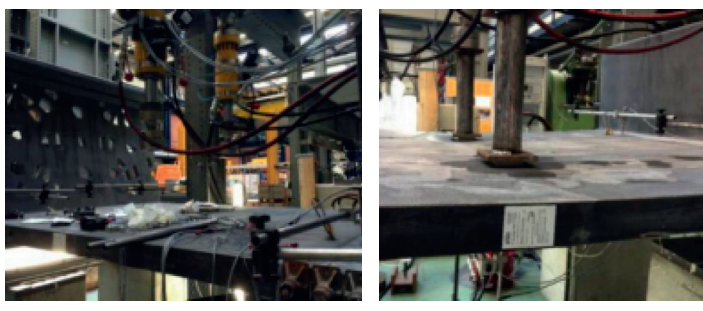

(a)
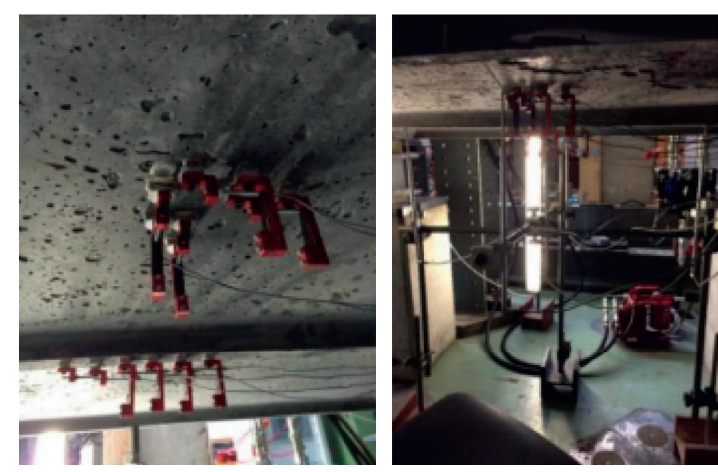

(b)

Figure 3: Measurement and loading processes of the test model. (a) Measurement and loading at the model top. (b) Measurement and loading at the model bottom.

TABle 1: Actual loading values.

\begin{tabular}{lcc}
\hline Load range of single loading point & Load unit & Note \\
\hline $0 \sim 20 \mathrm{kN}$ & $2 \mathrm{kN}$ & Limit bearing capacity of the one-way slab, observe initial cracks \\
$20 \mathrm{kN} \sim 50 \mathrm{kN}$ & $5 \mathrm{kN}$ & \\
$50 \mathrm{kN} \sim 60 \mathrm{kN}$ & $2 \mathrm{kN}$ & Ultimate bearing capacity of the two-way slab, observe cracks \\
$60 \mathrm{kN}$ to END & Displacement control & The deformation increases while the load application does not grow \\
\hline
\end{tabular}

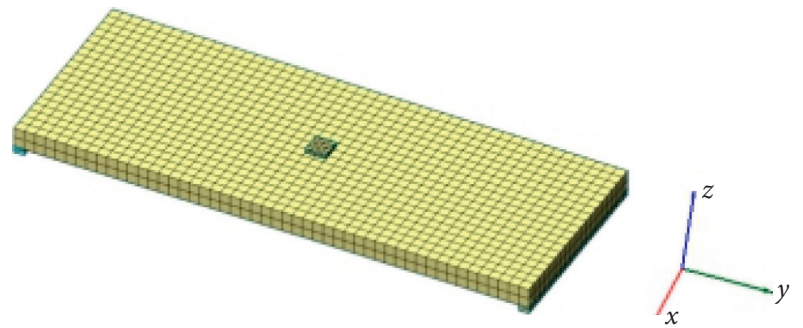

FIGURE 4: The established FEM.

3.3. Boundary Conditions and Load Application. Since the U-beam test member was placed between the two supporting steel beams, and the strip wood blocks were placed between the steel beams and the member, when simulating the boundary conditions of the FEM, a set of nodes in the left and right longitudinal directions were set up to impose the boundary conditions. The displacements in the $x$ and $z$ directions of the left and right node sets were limited. The $y$-direction displacement and rotation constraints were released to simulate the boundary conditions in the actual U-beam test. The steel loading blocks were set at the central point to relieve the local stress concentration. In the numerical simulation analysis, displacement load control was used to obtain the descending section curve along the normal direction of the loading block. Since the maximum displacement value corresponding to the load-displacement curve obtained by the test was $90 \mathrm{~mm}$, a total displacement of $100 \mathrm{~mm}$ in the $z$-direction is applied at the loading point of the steel loading block to simulate the concentrated force so as to the stress characteristics of the half $U$ beam.

\section{Mechanical Properties of Prestressed UHPFRC U Beam}

4.1. Failure Mode. In the full-scale prestressed UHPFRC U beam, in the period from the test beginning to the failure, first, a large number of fine cracks developed at the loading center. The cracks appeared at the subsurface bottom plate, and the first visible crack appeared at the central rib, eventually forming several visible longitudinal and vertical cracks. The maximum vertical crack was connected with a longitudinal crack. The failure mode is shown in Figure 6.

The U-beam failure mode represented a transverse bending along the longitudinal bottom axis. There were obvious longitudinal cracks on the top and bottom surfaces, and the cracks developed around the two concentrated loading positions. The cracks were numerous and dense, and the largest crack occurred in the central rib. The growth rate of the crack width at the rib was greater than that at the bottom. Based on the results of the failure mode of the component under the external load, the middle bottom plate bore part of the load, while the other part of the load was transferred to two free edges where the rib plate was located, which was borne by the rib plate.

The top, bottom, and rib crack distribution diagrams obtained according to the fracture morphology are presented in Figure 7. As shown in Figure 7(a), the top surface crack spacing was small, relatively concentrated, and dense. There were only a few visible cracks around the loading points on the bottom. When the central point crack developed at about half-length from the free side, the fracture became dispersed and obtained a triangular shape. The bottom crack distribution was more dispersed and extensive than that on the top surface, but most of the cracks were 


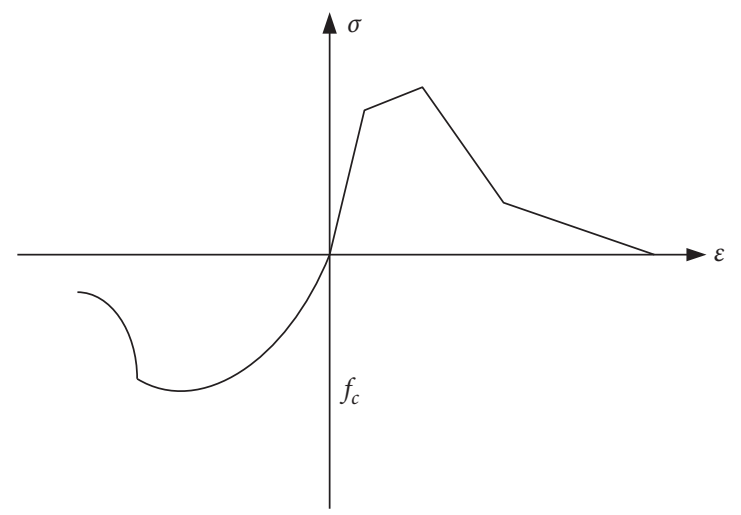

(a)
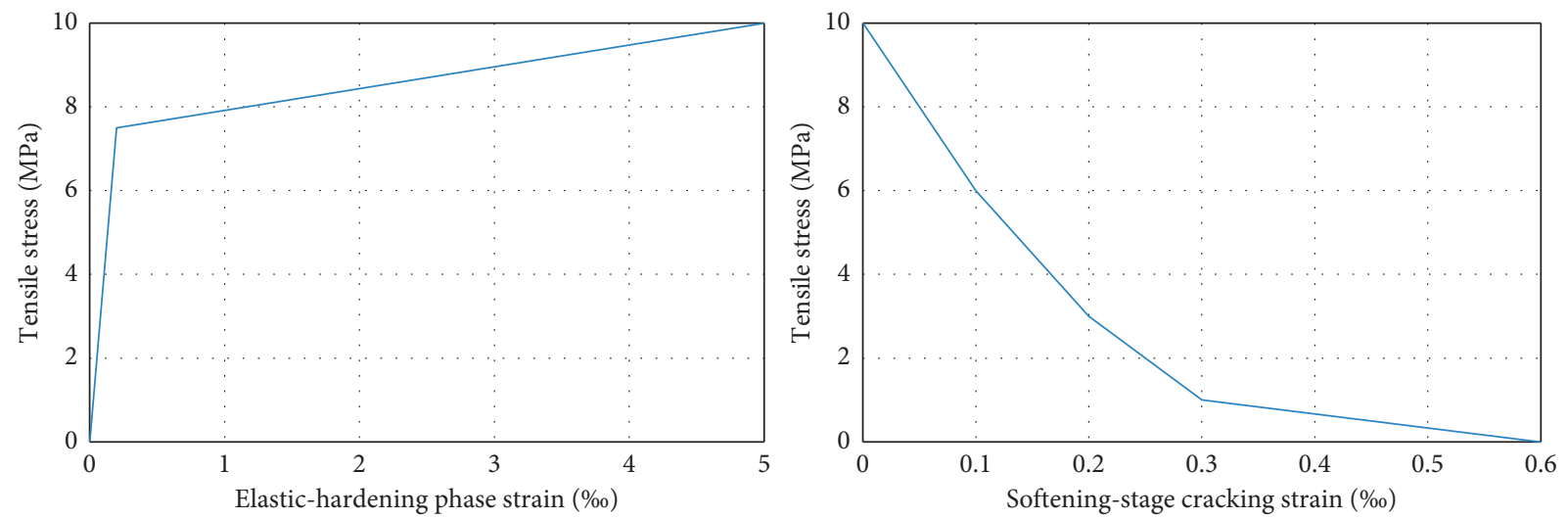

(b)

FIgURE 5: Constitutive relation model of the UHPFRC. (a) Tensile and compression constitutive model of the UHPFRC. (b) Tensile constitutive relation in the numerical model of the UHPFRC.

TABLE 2: Material characteristic parameters.

\begin{tabular}{|c|c|c|c|c|c|c|c|}
\hline UHPFRC & $\begin{array}{c}f_{\text {Ute }}(\mathrm{MPa}) \\
6.5 \\
\end{array}$ & $\begin{array}{c}f_{\text {Utu }}(\mathrm{MPa}) \\
10\end{array}$ & $\begin{array}{c}\mathcal{E}_{\text {Ute }}(\% o) \\
0.15\end{array}$ & $\begin{array}{c}\mathcal{E}_{\mathrm{Uts}}(\% 0) \\
2.0 \\
\end{array}$ & $\begin{array}{c}\mathcal{E}_{\mathrm{Utu}}(\% \mathrm{o}) \\
5.0\end{array}$ & $\begin{array}{c}f_{\text {Ucu }}(\mathrm{MPa}) \\
150\end{array}$ & $\begin{array}{c}E_{\mathrm{U}}(\mathrm{GPa}) \\
50\end{array}$ \\
\hline Ordinary steels & $\begin{array}{c}f_{\text {sy }}(\mathrm{MPa}) \\
500\end{array}$ & $\begin{array}{c}f_{\text {su }}(\mathrm{MPa}) \\
510\end{array}$ & $\begin{array}{c}\varepsilon_{\text {sy }}(\% 0) \\
2.19\end{array}$ & $\begin{array}{c}\varepsilon_{\text {sy }}(\% o) \\
100\end{array}$ & $\begin{array}{c}E_{\mathrm{s}}(\mathrm{GPa}) \\
205\end{array}$ & $\phi\left(\begin{array}{c}\mathrm{mm}) \\
14\end{array}\right.$ & $\begin{array}{l}N \\
2\end{array}$ \\
\hline Prestressed steels & $\begin{array}{c}f_{\text {sy }}(\mathrm{MPa}) \\
760\end{array}$ & $\begin{array}{c}f_{\text {su }}(\mathrm{MPa}) \\
1860\end{array}$ & $\begin{array}{c}\varepsilon_{\text {sy }}(\% o) \\
2.19\end{array}$ & $\begin{array}{c}\varepsilon_{\text {su }}(\%) \\
100\end{array}$ & $\begin{array}{c}E_{\mathrm{s}}(\mathrm{GPa}) \\
195\end{array}$ & $\begin{array}{c}\phi(\mathrm{mm}) \\
15.2\end{array}$ & $\begin{array}{c}N \\
6\end{array}$ \\
\hline
\end{tabular}

distributed around the rib plate, as shown in Figure 7(b). The rib crack distribution was similar to that of the suitable reinforcement beam. The cracks appeared on the whole rib, and they were evenly distributed, as shown in Figures 7 (c) and $7(\mathrm{~d})$.

4.2. Deflection Development. The load-central displacement curves under the combined action of two concentrated loads (Force 1 and Force 2 ) acting on the $1 / 2 \mathrm{U}$ beam are presented in Figure $8(\mathrm{a})$. The bearing capacity of the $1 / 2 \mathrm{U}$ beam under Force 1 was always greater than that under Force 2, and the corresponding ultimate bearing capacities were $F 1=74.77 \mathrm{kN}$ and $F 2=63.62 \mathrm{kN}$, respectively. Therefore, the U-beam ultimate bearing capacity reached a value of $138.39 \mathrm{kN}$, and the maximum central displacement was
$90 \mathrm{~mm}$. The load-displacement curves of the rib at each web side and the two loading points are shown in Figure 8(b), where it can be seen that the deformations measured by the two displacements at the fourth points were consistent. The maximum displacement was $50 \mathrm{~mm}$, indicating that the rib stress in the loading process was uniform.

4.3. Strain Development. Since the component was symmetrical along the central rib, only transverse and longitudinal strains at the bottom plate were considered, as shown in Figure 9. As shown in Figure 9(a), when the central displacement was less than $75 \mathrm{~mm}$, the strain value of the transverse measuring point No. 1 was always greater than that of the longitudinal measuring point No. 1, but when the central displacement reached a value of $75 \mathrm{~mm}$, the strain 


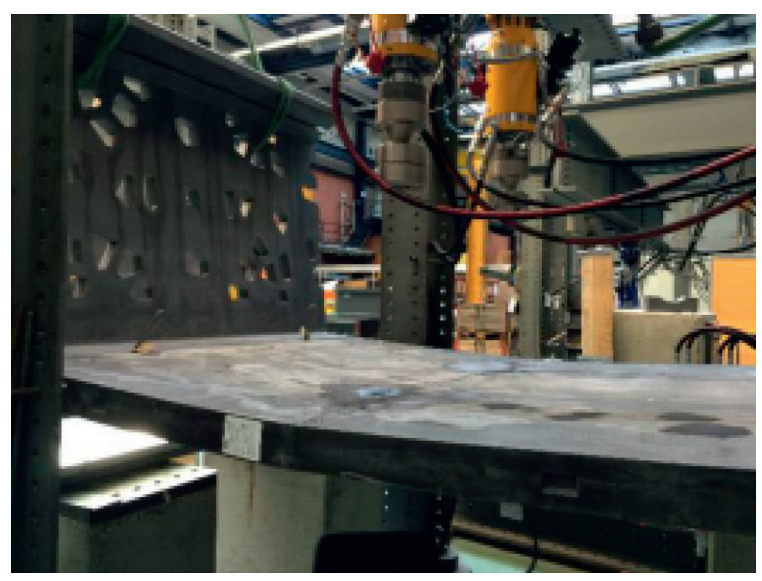

(a)

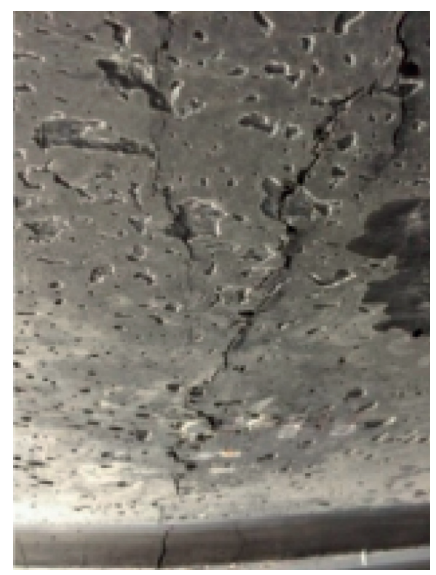

(b)

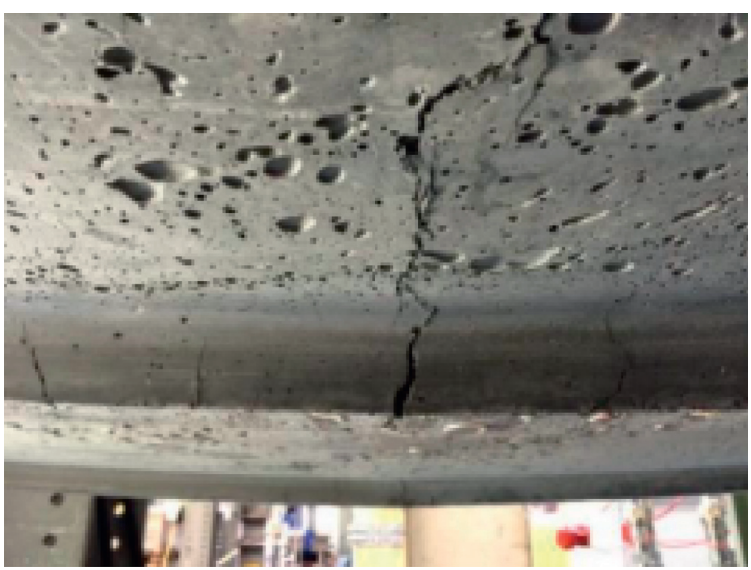

(c)

Figure 6: Failure modes of the U-beam test. (a) Top surface failure of the bottom plate (b) Bottom surface failure of the bottom plate. (c) Bottom rib failure.

value of the transverse measuring point No. 2 exceeded that of the transverse measuring point No. 1 . When the displacement reached a value of $80 \mathrm{~mm}$, the maximum strain value of $16.3 \%$ was at the transverse measuring point No. 2 . The minimum strain value of $1.3 \%$ was obtained at the longitudinal measuring point No. 2, which was far less than the ultimate tensile strain of UHPFRC of 5.0\%. Therefore, the cross-section around the longitudinal measuring point No. 2 was not cracked, and the transverse strains were greater than the longitudinal strains in the whole test process. Thus, the transverse deformation at the bottom was greater than the longitudinal one.

As shown in Figure 9(b), the longitudinal strain difference increased during the test, and the maximum difference was $7.1 \%$, while the transverse strain difference first increased and then decreased, and the maximum difference of $4.0 \%$ occurred at the central displacement of $42.4 \mathrm{~mm}$. The transverse deformations at the bottom were more evenly distributed than the longitudinal deformations in the loading point area.

The displacement strain curves measured by five strain gauges at the central bottom rib are shown in Figure 9(c). From the loading beginning to the displacement of $20 \mathrm{~mm}$, the strain values measured at five measuring points had small differences, showing a linear change, and the strain value at measuring point No. 3 was the largest. However, after the central displacement reached a value of $32 \mathrm{~mm}$, the strain value at measuring point No. 2 exceeded that of measuring point No. 4 and remained at its maximum value. Due to the influence of the loading block, the strain change at the central rib was not obvious and mainly occurred at the measuring points No. 2 and No. 4, showing a linear change. The strain value at the measuring points No. 1 and No. 5 decreased after reaching the maximum value of $5.0 \%$. The strain curves of the measuring points No. 1, No. 5, No. 2, and No. 4 were similar to that of measuring point No. 3 . The U-beam deformation was symmetrical to the central rib, but the deformation of the low-web side was greater than that of the high-web side.

\subsection{Discussion}

4.4.1. Displacement. The $1 / 2$ U-beam central displacement calculated by the nonlinear FEM was compared with the central displacement under Force 1 and Force 2 obtained by the test. The comparison of the load-displacement curves is shown in Figure 10, where it can be seen that the changing 


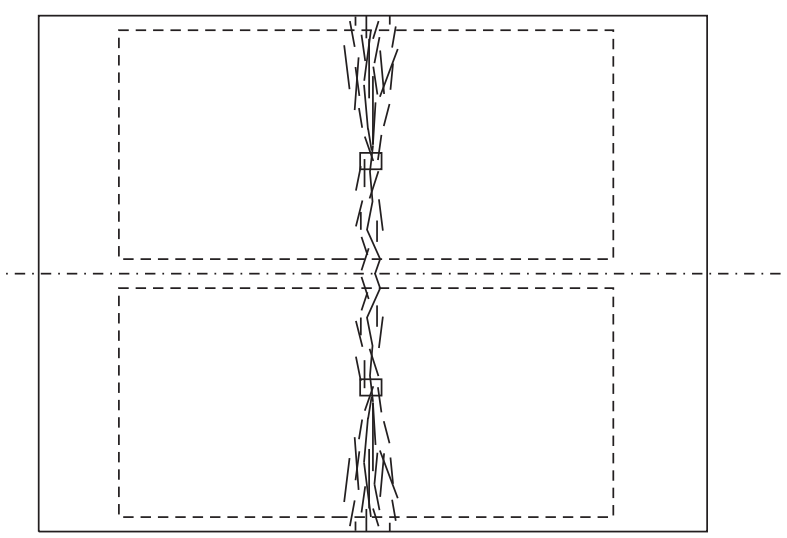

(a)

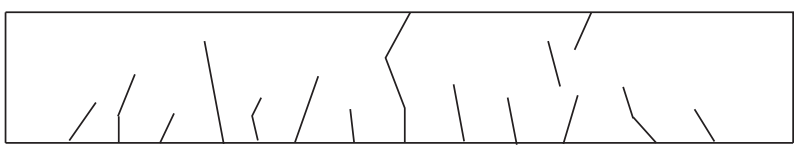

(c)

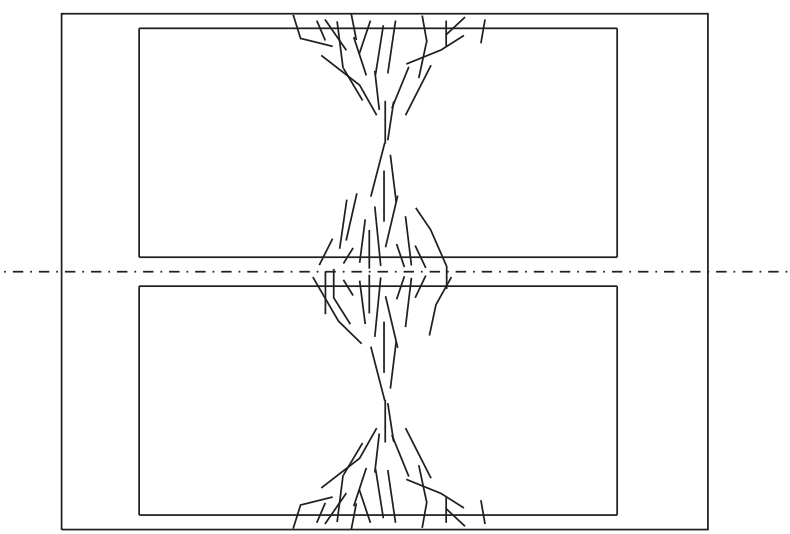

(b)

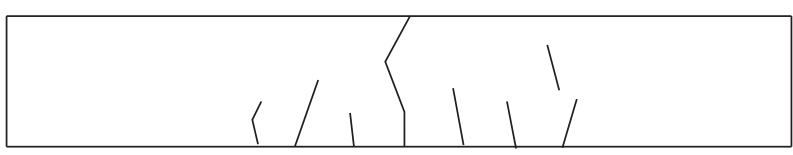

(d)

Figure 7: Crack distribution diagrams. (a) Crack distribution on the top surface. (b) Crack distribution on the bottom surface. (c) Crack distribution on the bottom rib. (d) Crack distribution on the bottom edge.

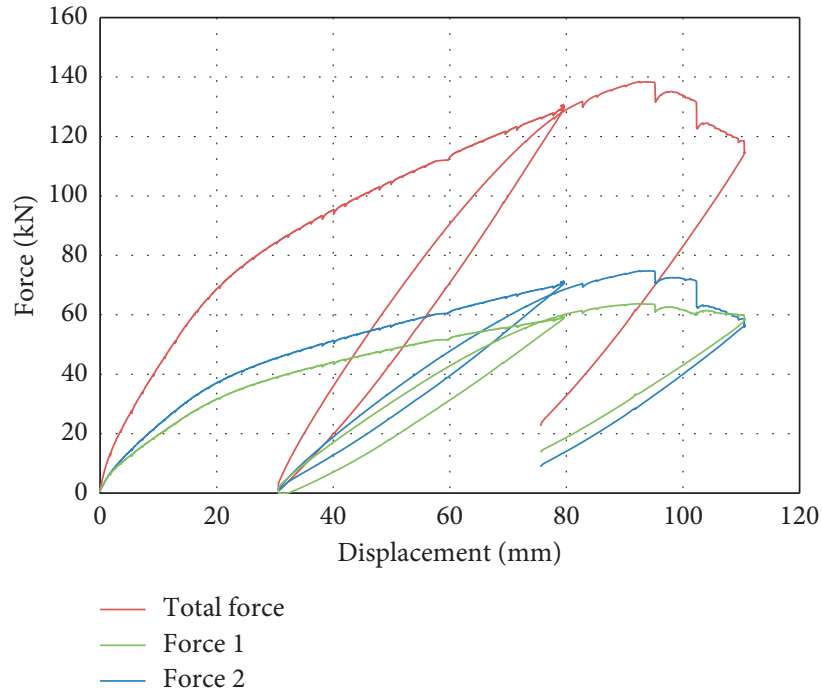

(a)

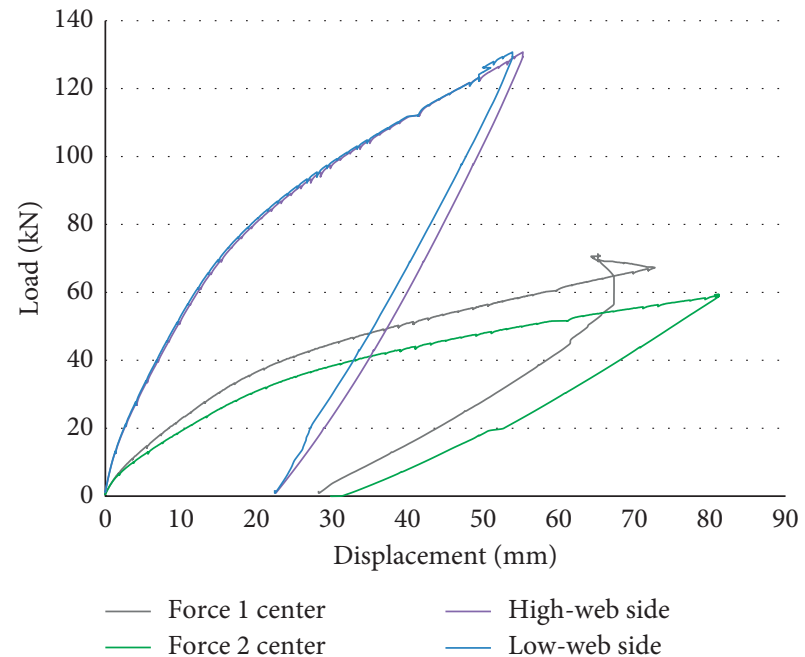

(b)

Figure 8: Load-displacement curves. (a) Member center displacement. (b) Rib and loading center displacements.

trend of the FEM load-displacement curves was consistent with that of the test results, which was between test loaddisplacement curves obtained under two concentrated forces. When displacement was less than $10 \mathrm{~mm}$, the FEM curve changed the same as the Force 1 curve. However, when the displacement reached a value of $80 \mathrm{~mm}$, the maximum bearing capacities of Force 1, Force 2, and FEM did not differ significantly, and they were $69.7 \mathrm{kN}, 61.4 \mathrm{kN}$, and $59.3 \mathrm{kN}$, respectively. Thus, the established nonlinear FEM could simulate the actual stress reasonably.
4.4.2. Strain. The strain obtained by the nonlinear numerical simulation was compared with the measured data, and the transverse and longitudinal load strain curves are shown in Figures 11(a) and 11(b). The changing trend of the transverse load strain was in good agreement with the test strain rule, especially the two transverse strain curves of the measuring point No. 2 almost coincided. The changing trend of longitudinal strain in the early stage was similar, the measured strain was larger than that of the FEM, but the difference was significant in the later stage. 


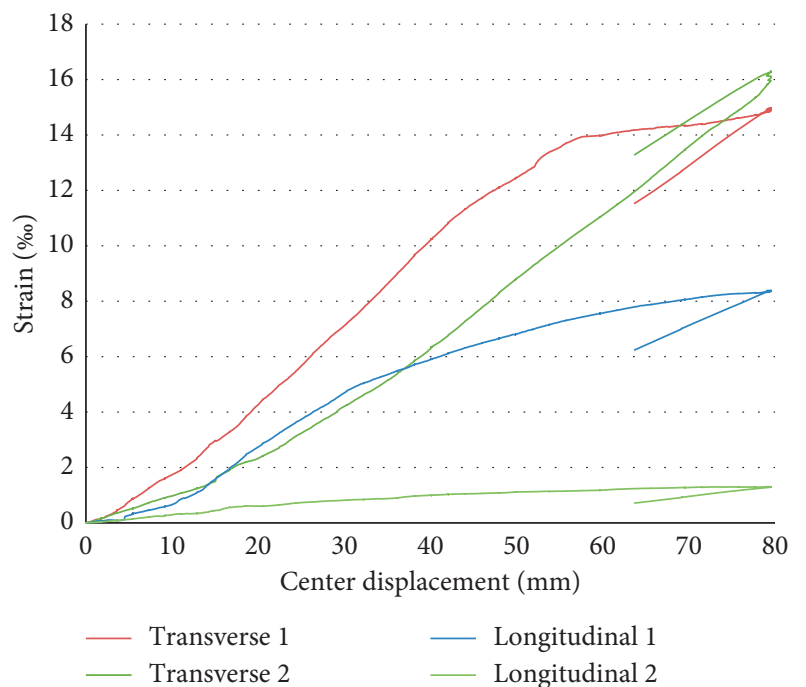

(a)

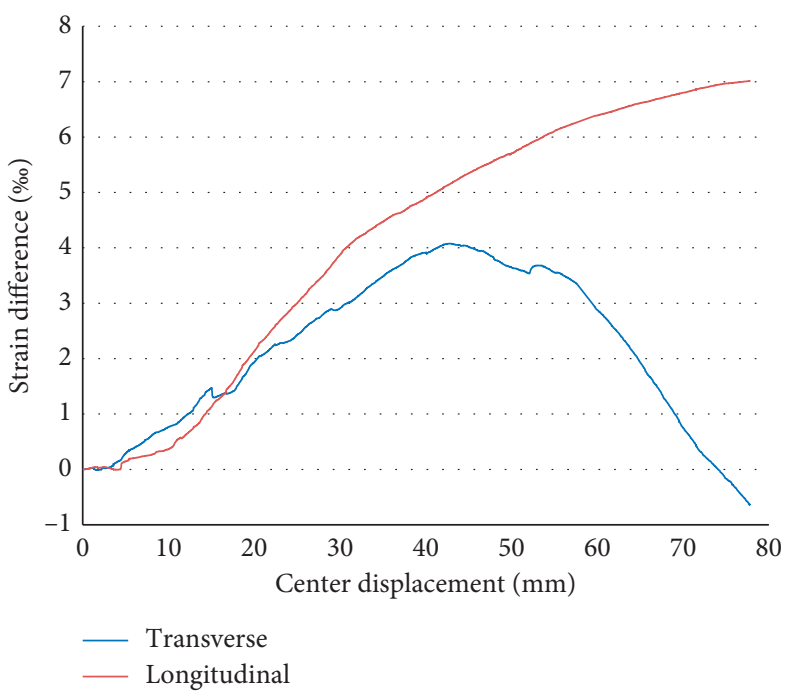

(b)

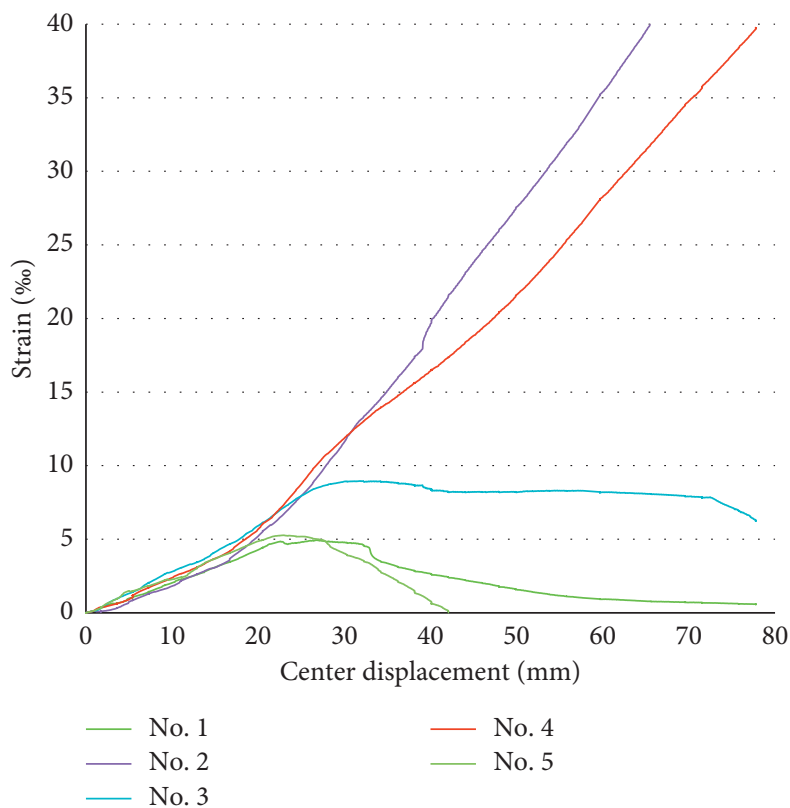

(c)

Figure 9: Strain-displacement curves. (a) Load point strain. (b) Transverse and longitudinal strain differences. (c) Costal board strain.

In addition, because the numerical model was simulated by taking half of the central symmetry of the test members along the transverse symmetry axis, the FEM stiffness was greater than that of the test. Moreover, the longitudinal strain difference was large, and the maximal longitudinal strain value of the test was significantly smaller than that of the FEM, having a maximum difference of $2 \%$. The longitudinal stiffness of the numerical model in the early loading stage was larger than the transverse stiffness, and Force 1 and Force 2 had a joint influence on the longitudinal deformation on the plates, but the influence on the transverse deformation was not significant. At the later loading stage, the anisotropy of the UHPFRC material was relatively obvious, and the longitudinal distribution of steel fibers in the material could inhibit the deformation development.
The comparative analysis showed that the nonlinear FEM could accurately simulate the component mechanical performance. In order to understand the strain distribution and development trend of the loading process more clearly, the bottom-element central strain with the loading coefficients of $0.2,0.4,0.6$, and 0.8 in the numerical model was analyzed, and the results are shown in Figures 12(a)-12(c). Since the numerical model was a symmetrical structure, half of the strain curve was along the longitudinal direction. The transverse axis denoted the ratio of the distance between a measuring point and the central point to the half transverse length. The smaller the ratio was, the closer the measuring point was to the central point.

The strain distribution along the bottom transverse centerline is shown in Figure 12(a). Because the loading 


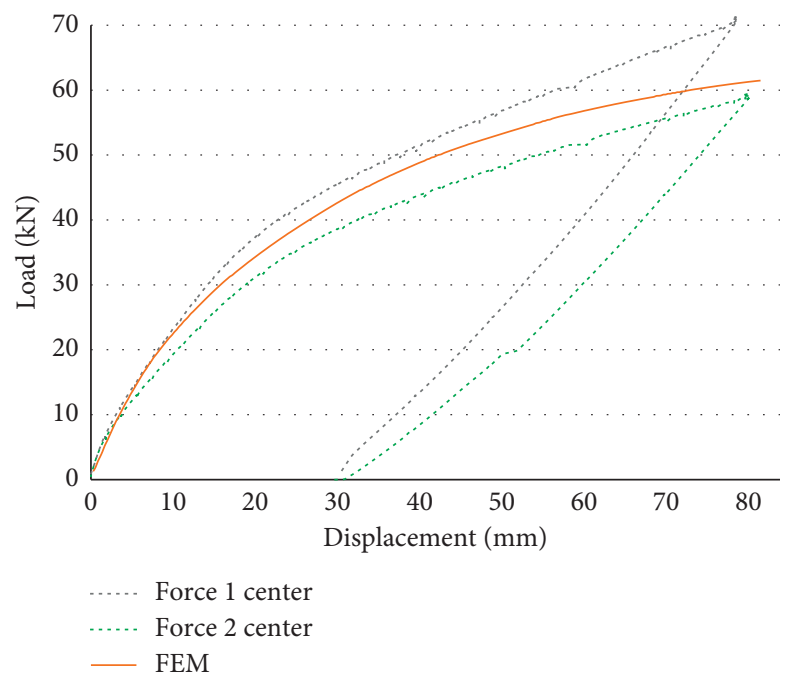

FIGURE 10: The comparison of the experimental and FEM load-displacement curves.

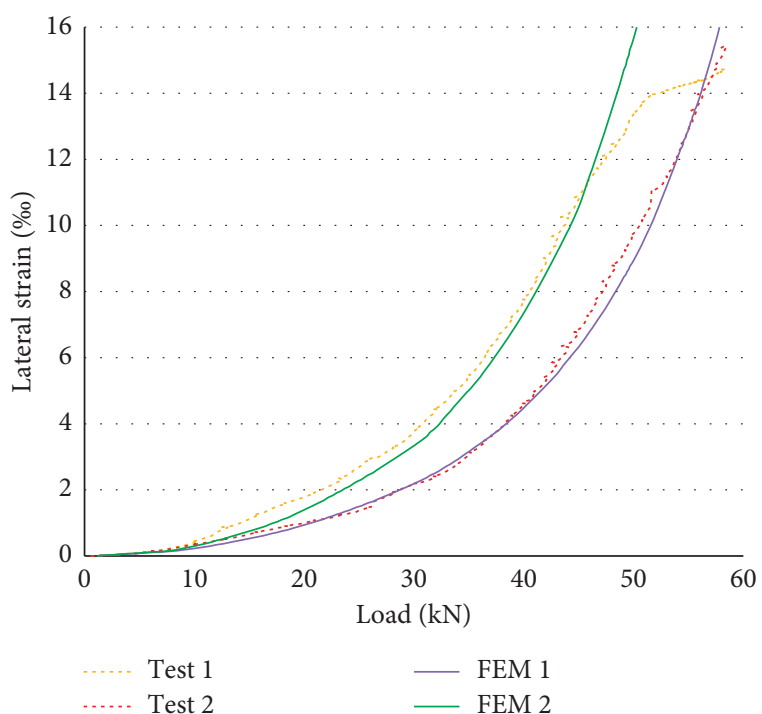

(a)

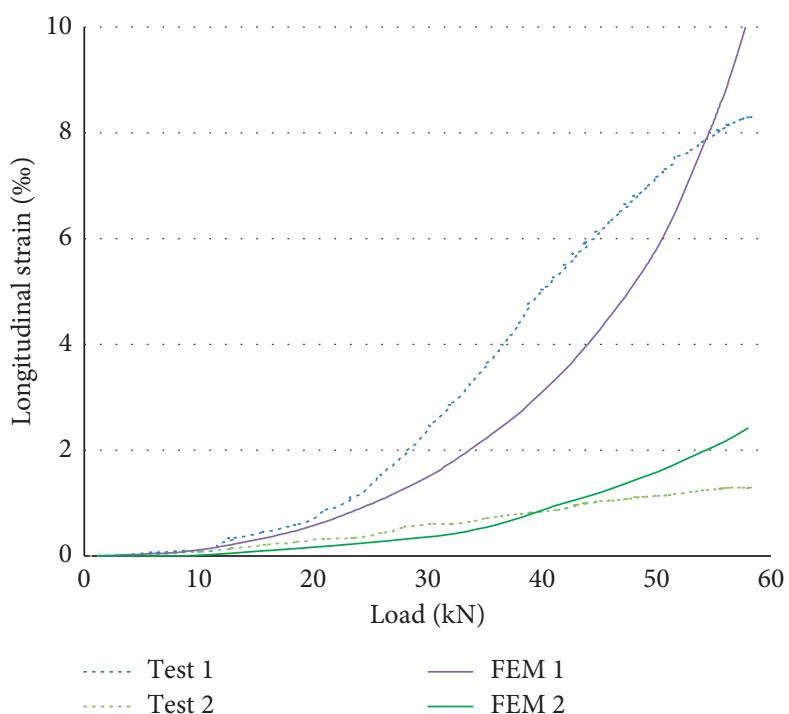

(b)

Figure 11: Experimental and FEM load strain curves. (a) Transverse strain comparison. (b) Longitudinal strain comparison.

block was always in the elastic deformation stage, the strain value of the central point element was smaller than that of the second-nearest measuring point to the center point. The strain changed slightly at the other points, and the further from the center point the measuring point was, the slower the strain value increased. From the above analysis, it can be concluded that the load transmitted along the longitudinal direction under the concentrated load was mainly borne by the center bottom. When the loading coefficient was 0.8 , the distance ratio was 0.11 , and the crack development area on the transverse plate was $0.11 \times 1250 \mathrm{~mm}=137.5 \mathrm{~mm}$, which was about one-tenth of the transverse plate length.

The strain distribution along the longitudinal centerline is shown in Figure 12(b). The strain change occurred at the center rib (the last measuring point), reaching the maximum value of $19 \%$, which was much higher than the nonrib strain value. Therefore, in the deformation process, most of the load was transferred to the rib, which bore the burden, while the rest of the load was borne by the bottom plate. The greater the load was, the more significant the strain change was. The strain value of the center rib increased rapidly, while that of the plate changed uniformly along the longitudinal direction, and the strain difference between adjacent measuring points was small. Under the joint action of the two forces, the load transferred along the transverse direction was mainly borne by the center bottom plate and rib. Taking the strain value that was $5 \%$ greater than the ultimate tensile strain value as the main longitudinal development crack region, the distance to the center ratio was 0.72 , so the crack development area was $0.72 \times 471 \mathrm{~mm}=339.1 \mathrm{~mm}$, which was about two-thirds of the longitudinal plate length, and it was larger than that of the transverse development crack area, so 


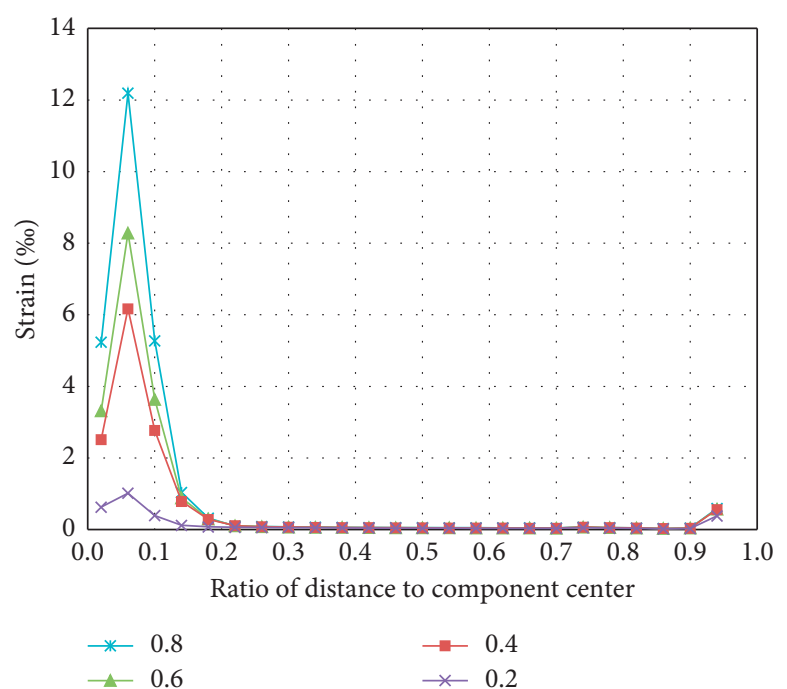

(a)

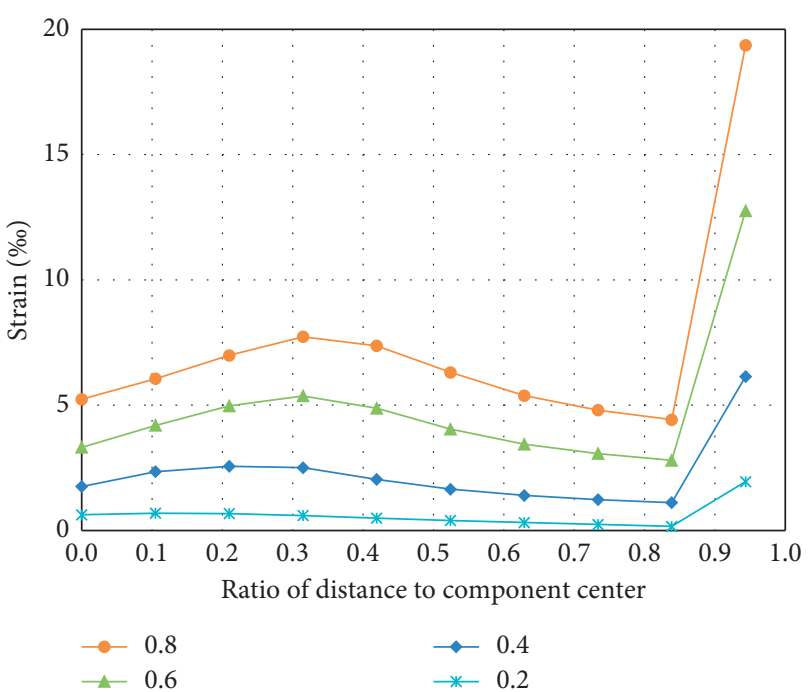

(b)

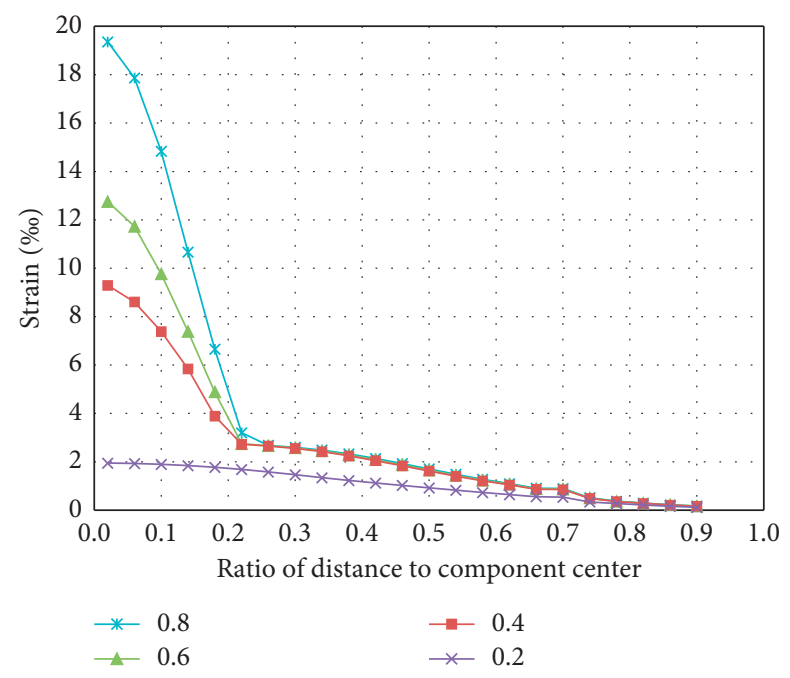

(c)

Figure 12: FEM strain curves. (a) Transverse central strain of the FEM. (b) Longitudinal central strain of the FEM. (c) Rib strain of the FEM.

the component mainly deformed along the longitudinal direction.

The rib strain distribution is shown in Figure 12(c). Different from the transverse and longitudinal centerline strain curves, the first measuring point was the actual rib center deformation position, which was also the maximum deformation location. According to the four obtained curves, when the loading coefficient was 0.2 , the strain curve changed relatively slowly, and the strain values at adjacent measuring points had a small difference. When the distance ratio from the center of the rib was from 0.26 to 0.9 , the strain curves at the loading coefficients of $0.4,0.6$, and 0.8 coincided, and the deformation around the rib could be ignored. In contrast, the strain value at the position before the measuring point having a distance from the center ratio of 0.26 increased linearly. The strain of the curve increased rapidly at the measuring points with the distance ratio of zero to 0.26 from the center of the rib, while the strain changed slowly at the other measuring points.
The farther the distance from the central point was, the less the strain value was. The rib crack development distance was $0.2 \times 1250 \mathrm{~mm}=250 \mathrm{~mm}$, which was about one-fifth of the rib length. Therefore, the deformations mainly occurred at the bottom, and cracks first appear at the rib and then around the loading center.

4.4.3. Failure Mode. The main fracture development regions of the FEM are plotted in Figure 13. Compared with the fracture distribution mode obtained from the test (Figure 7), it has the following characteristics:

(1) The distribution range of cracks of the FEM was similar to that of the actual rib, but there were visible cracks in the whole central rib and only in the middle part of the edge rib, as shown in Figure 13(a).

(2) The FEM and test results show that cracks on the top surface developed longitudinally along the loading 


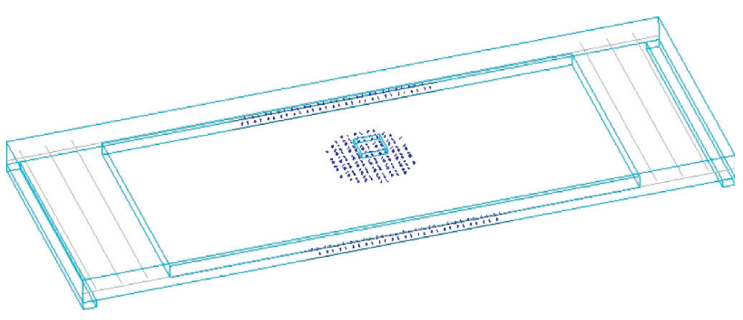

(a)

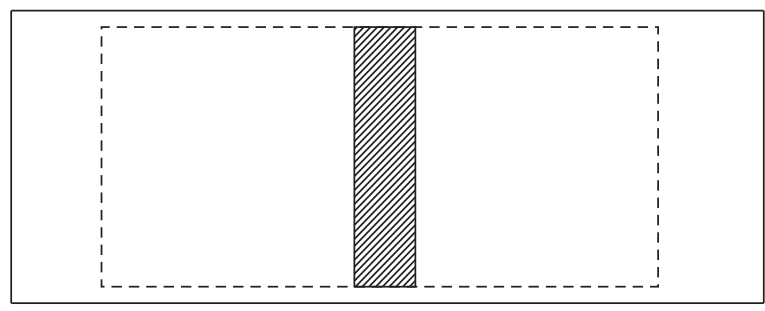

(b)

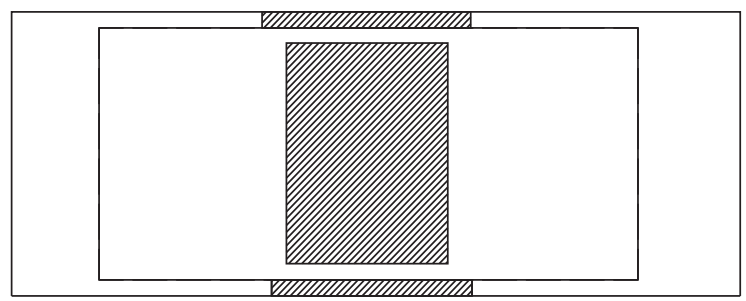

(c)

Figure 13: The main fracture regions of the FEM. (a) Fracture development model. (b) Top fracture development area. (c) Bottom fracture development area.

block, as shown in Figure 13(b). In the test, the top surface crack width was the same as that of the loading block, and in the FEM analysis, the top surface crack width was larger than the loading block width, and the top surface crack development range was smaller than that of the bottom surface.

(3) The bottom cracks developed in the center rectangle and rib area. In the FEM, cracks on the underside were mainly concentrated in the central rectangular region, as shown in Figure 13(c). In the test, there were a number of triangular cracks on the bottom plate extending to the edge rib, but the more cracks were developed, the more dispersed the crack distribution was. Moreover, due to the rib-cracking impact, there were more microcracks on the inner edge than in the loading center.

\section{Ductility Analysis of Prestressed UHPFRC U Beams}

As mentioned previously, due to the U-beam symmetry, only half section was taken for the analysis and calculation.
The UHPFRC had ultra-high compressive strength, so the interface was equivalent to the first type of T-shaped section. The calculation diagrams are shown in Figures 14(a)-14(c).

According to the simplified calculation diagram that is shown in Figure 14(c), the calculation equation of the height of section compression zone $x$ given by equation (1) and the ultimate bending moment given by equation (2) of the section compression zone were derived. The material strength was calculated according to the design value. The concrete material performance partial coefficient of the axial compressive and tensile strength specified in $[35,36]$ was set to 1.45 , and the material performance partial coefficient specified in $[37,38]$ was not less than 1.3 , so the material performance partial coefficient of the UHPFRC was taken as 1.3. In addition, when the ultimate bearing capacity of the UHPFRC structure was calculated, it was necessary to take into account the global size effect influence coefficient $K=1.75$, and the partial coefficient of reinforcement material performance was taken as 1.2 .

$$
\begin{aligned}
a \frac{f_{\mathrm{Ucu}}}{\gamma_{c}} b_{f} x= & \frac{f_{\mathrm{Utu}}}{K \gamma_{c}}\left(\frac{h}{2}-x\right) b_{f}+\frac{h f_{\mathrm{Utu}}}{2 K \gamma_{c}} b+\frac{f_{y}}{\gamma_{m}} A_{s}, \\
0.85 \times \frac{150 \mathrm{MPa}}{1.3} \times 705 \mathrm{~mm} \times x= & \frac{10 \mathrm{MPa}}{1.3 \times 1.75} \times\left(\frac{100 \mathrm{~mm}}{2}-x\right) \times 705 \mathrm{~mm} \\
& +\frac{100 \mathrm{~mm}}{2} \times \frac{10 \mathrm{MPa}}{1.3 \times 1.75} \times 105 \mathrm{~mm}+\frac{500 \mathrm{MPa}}{1.2} \times 308 \mathrm{~mm}^{2}, \\
x= & 4.24 \mathrm{~mm} .
\end{aligned}
$$




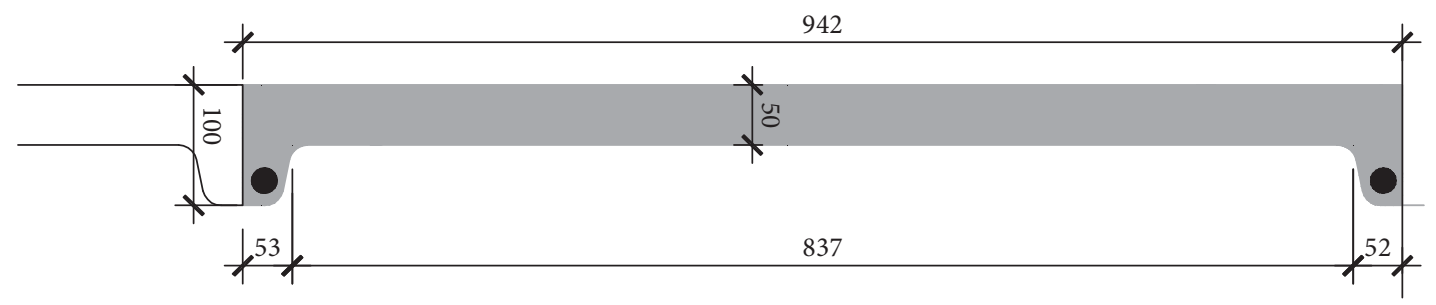

(a)

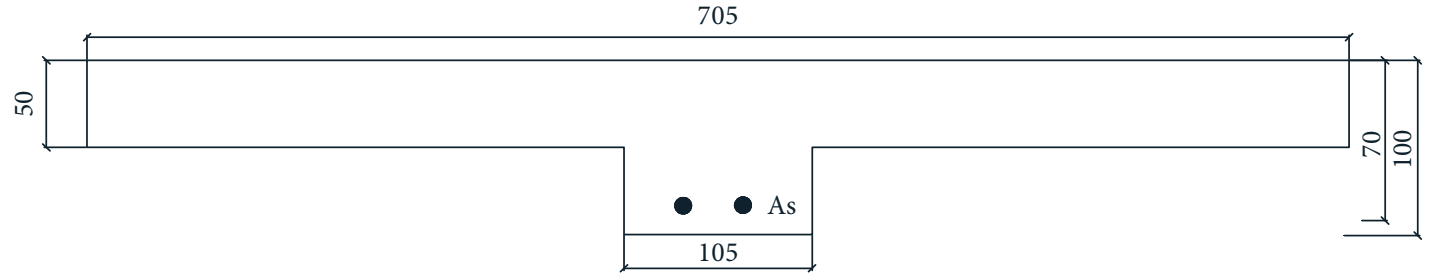

(b)

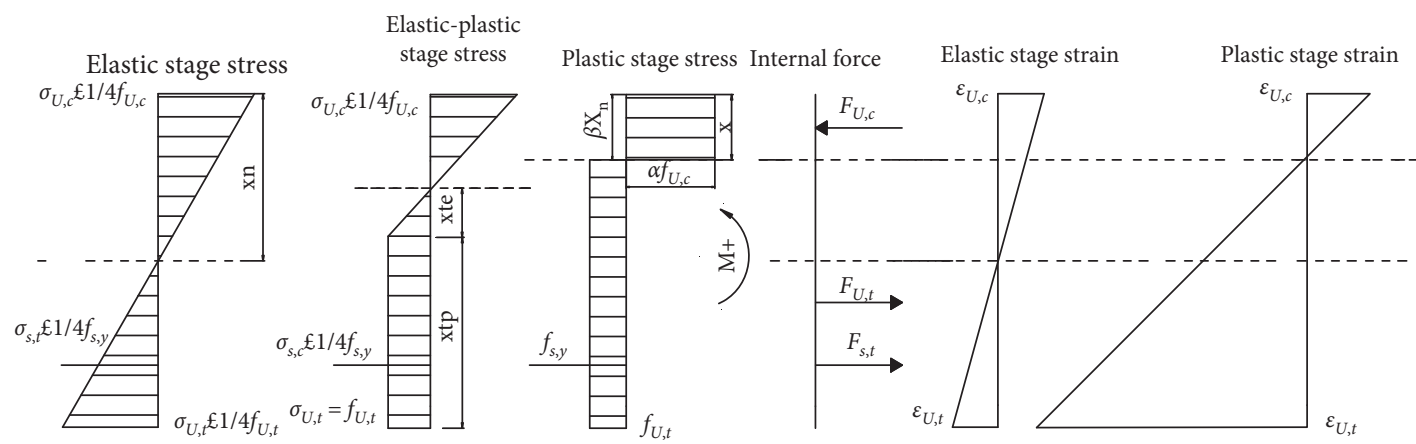

(c)

Figure 14: The theoretical calculation difficulty diagram. (a) Half longitudinal section (unit: mm). (b) Converted section (unit: mm). (c) Simplified calculation of the limit state calculation.

By substituting the calculated height of the compression zone into equation (2), the ultimate bending moment was obtained as follows:

$$
\begin{aligned}
M_{u}= & \frac{f_{y}}{\gamma_{m}} A_{S}\left(h_{0}-\frac{x}{2}\right)+\frac{h f_{\mathrm{Utu}}}{4 K \gamma_{c}}\left(\frac{h}{2}-x\right) b_{f}+\frac{h^{2} f_{\mathrm{Utu}}}{4 K \gamma_{c}} b \\
= & \frac{500 \mathrm{MPa}}{1.2} \times 308 \mathrm{~mm}^{2} \times\left(70 \mathrm{~mm}-\frac{4.24 \mathrm{~mm}}{2}\right)+\frac{100 \mathrm{~mm}}{4} \times \frac{10 \mathrm{MPa}}{1.3 \times 1.75} \\
& \times\left(\frac{100 \mathrm{~mm}}{2}-4.24 \mathrm{~mm}\right) \times 705 \mathrm{~mm}+\frac{(100 \mathrm{~mm})^{2}}{4} \times \frac{10 \mathrm{MPa}}{1.3 \times 1.75} \times 105 \mathrm{~mm} \\
= & 13.41 \times 10^{6} \mathrm{~N} \cdot \mathrm{mm}=13.41 \mathrm{kN} \cdot \mathrm{m} .
\end{aligned}
$$

Then, the ultimate bending moment per unit width was obtained as

$$
m_{u}=\frac{M_{u}}{B}=\frac{13.41 \mathrm{kN} \cdot \mathrm{m}}{0.942 \mathrm{~m}}=14.24 \frac{\mathrm{kN} \cdot \mathrm{m}}{\mathrm{m}} .
$$

Based on the FEM and experimental failure modes, the virtual work principle was used as the theoretical basis, and boundary conditions were simply supported on two opposite sides. Suppose that the slab length was $L$ and its width was $B$, and the concentrated load acted on the centerline; then, the possible ductile slab failure modes I and II under the concentrated load would be as shown in Figure 15. The ultimate bearing capacity equation $P_{U}$ was derived to predict the ultimate flexural capacity, in which the ultimate positive and negative resistance slab moments were denoted by $m_{u}$ and $m_{u}^{\prime}$, respectively. 


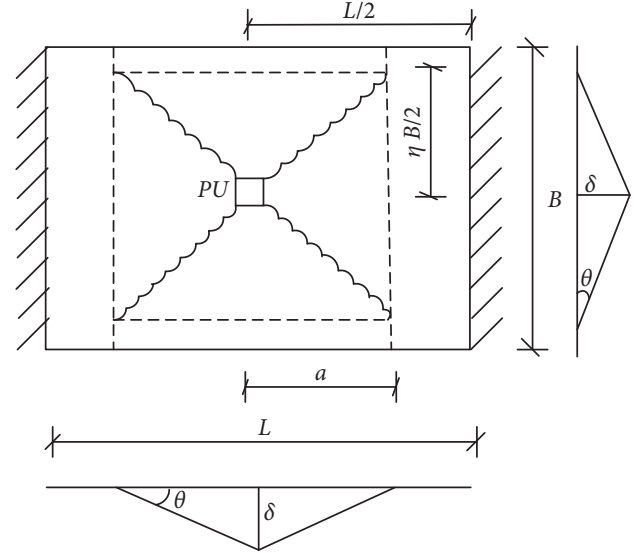

(a)

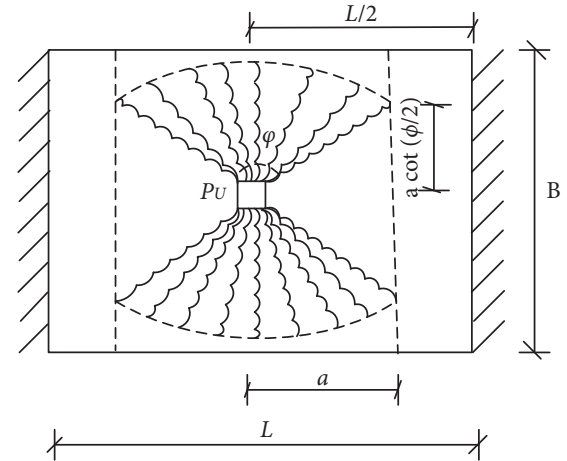

(b)

FIgURE 15: The theoretical analysis of failure patterns. (a) Failure pattern I (b) Failure pattern II.

5.1. Failure Mode I. Failure mode I could be divided into four triangle plates by the yield line plate. Assume that in the direction of the long side of the plate, the distance of the yield line from the center was denoted by $a$, while the distance of the short edge of the yield line from the center was denoted by $\eta B / 2$, where $0<\eta \leq 1$, and the ultimate bearing capacity of mode I was denoted by $P_{U, I}$. Then, as shown in Figure 15(a), the displacement caused by the load was $\delta$, but since this work mainly considered the bending moment on the four triangular plates, the virtual work equation was given by

$$
\begin{aligned}
P_{U . I} \delta & =2 m_{u} \frac{\delta}{\eta B / 2} \cdot 2 a+2\left(m_{u}^{\prime}+m_{u}\right) \frac{\delta}{a} \eta B, \\
P_{U, I} & =\frac{8 a m_{u}}{\eta B}+\frac{2 \eta B\left(m_{u}^{\prime}+m_{u}\right)}{a} .
\end{aligned}
$$

When the minimum $P_{U, I}$, there is $\mathrm{d} P_{U, I} / \mathrm{d} a=0$.

$$
\frac{\mathrm{d} P_{U, I}}{\mathrm{~d} a}=\frac{8 m_{u}}{\eta B}-\frac{2 \eta B\left(m_{u}^{\prime}+m_{u}\right)}{a^{2}}=0 .
$$

Therefore,

$$
a=0.5 \eta B \sqrt{\frac{m_{u}^{\prime}+m_{u}}{m_{u}}} .
$$

So,

$$
P_{U, I}=4(1+\eta) \sqrt{m_{u}\left(m_{u}^{\prime}+m_{u}\right)}
$$

5.2. Failure Mode II. Failure mode II consisted of two fan-shaped parts; the central angle was denoted by $\phi$, and the yield line edge from the board center size was denoted by $a$; the ultimate bearing capacity of mode II was $P_{U, I I}$, as shown in Figure 15(b). This work was mainly done by bending the moments of the two parts and the area between them, so the virtual work equation was as follows:

$$
\begin{aligned}
P_{U, I I} \delta & =2 m_{u} \frac{\delta}{a} \cdot 2 a \cdot \cot \frac{\phi}{2}+2\left(m_{u}^{\prime}+m_{u}\right) \delta \phi, \\
P_{U, I I} & =4 m_{u} \cot \frac{\phi}{2}+2\left(m_{u}^{\prime}+m_{u}\right) \phi .
\end{aligned}
$$

When the minimum $P_{U, I I}$, then $\mathrm{d} P_{U, I I} / \mathrm{d} \phi=0$.

$$
\frac{\mathrm{d} P_{U, I I}}{\mathrm{~d} \phi}=-2 m_{u} \csc ^{2} \frac{\phi}{2}+2\left(m_{u}+m_{u}^{\prime}\right) \phi=0 .
$$

Therefore,

$$
\begin{aligned}
& \csc ^{2} \frac{\phi}{2}=\frac{m_{u}^{\prime}+m_{u}}{m_{u}}=1+\frac{m_{u}^{\prime}}{m_{u}}, \\
& \cot \frac{\phi}{2}=\sqrt{\frac{m_{u}^{\prime}}{m_{u}}}
\end{aligned}
$$

When $m_{u}^{\prime}=m_{u}$,

$$
\cot \frac{\phi}{2}=\sqrt{\frac{m_{u}^{\prime}}{m_{u}}}=1, \quad \phi=\frac{\pi}{2} .
$$

Thus, the ultimate load formulas of failure modes I and II were as follows:

$$
\begin{aligned}
P_{U, I} & =4(1+\eta) \sqrt{2 m_{u}^{2}}=4 \sqrt{2}(1+\eta) m_{u} \sim(5.66,11.31] m_{u}, \\
P_{U, I I} & =4 m_{u}\left(1+\frac{\pi}{2}\right)=10.28 m_{u} .
\end{aligned}
$$

When $m_{u}^{\prime}=0$, then $\cot (\phi / 2)=\sqrt{m_{u}^{\prime} / m_{u}}=0, \phi=\pi$, and the two sectors in failure mode II were connected into a whole circle.

Therefore, the ultimate load formulas of failure modes I and II were as follows:

$$
\begin{aligned}
P_{U, I} & =4(1+\eta) \sqrt{m_{u}^{2}}=4(1+\eta) m_{u} \sim(4.0,8.0] m_{u}, \\
P_{U, I I} & =2 \pi \cdot m_{u}=6.28 m_{u} .
\end{aligned}
$$

The minimum values of ultimate bending capacity calculated for each failure mode are given in Table 3. 
TABLe 3: Extreme values of the flexural capacity.

\begin{tabular}{lcc}
\hline \multirow{2}{*}{ Conditions } & \multicolumn{2}{c}{ Ultimate bending capacity $P_{U}(\mathrm{kN})$} \\
& Failure mode I & Failure mode II \\
\hline$m_{u}^{\prime}=m_{u}$ & $(80.57,161.01]$ & 146.34 \\
$m_{u}^{\prime}=0$ & $(56.94,113.89]$ & 89.40 \\
\hline
\end{tabular}

The long-short side ratio of the half $\mathrm{U}$-shaped test beam was $2500 / 942=2.65$, so the value was in the range of $(2,3)$, which needed to be designed and calculated according to the two-way slab. When $m_{u}^{\prime}=0$, the intersection of the bearing capacity values of the two failure modes was $(56.94,89.40]$ $\mathrm{kN}$, and the average value of $73.17 \mathrm{kN}$ was taken as the theoretical ultimate bending capacity of the half U-shaped test beam. This value was close to the maximum value of $74.77 \mathrm{kN}$ obtained in the test, having a difference of only $2.1 \%$. Therefore, the theoretical calculation value of the ultimate bending capacity of the whole test model was $146.34 \mathrm{kN}$, which was $138.39 \mathrm{kN}$ higher than the actual test value, and the difference was $5.4 \%$.

\section{Conclusions}

The contributions of this work can be summarized as follows:

(1) The full-scale model test of the prestressed UHPFRC U-beam bridge is performed. The overall mechanical performance of a component is preliminarily defined. The UHPFRC characteristics under the static load and its influence on its bearing capacity, deformation, and cracks are explored, which plays a guiding role in the U-shaped structure applications in practical engineering.

(2) The ultimate bearing capacity values of the two loading points of the test model are $74.77 \mathrm{kN}$ and $63.62 \mathrm{kN}$, so the ultimate bearing capacity of the U beam is $138.39 \mathrm{kN}$, and the maximum displacement of the center is $90 \mathrm{~mm}$. When the displacement is $80 \mathrm{~mm}$, the maximum strain value is $16.3 \%$. Because the transverse deformation of the component is obvious, the longitudinal strain difference keeps increasing, with the maximum difference up to $7.1 \%$; the transverse strain difference shows a trend of first increasing and then decreasing, having the maximum difference of $4.0 \%$ at the center displacement of $42.4 \mathrm{~mm}$.

(3) The U beam is symmetrical and harmoniously deformed in the central rib, but the deformation on the low-web side is larger than that on the high-web side. The transverse deformation at the component bottom is more uniform than the longitudinal deformation. The crack distribution is triangular around the action point on the bottom surface of the $U$ beam, and it is a two-way plate failure. The maximum crack occurs at the central rib.

(4) The established nonlinear FEM can accurately simulate the structural deformation state in the stress process and define the existence and development of a crack. The maximum strain values are ordered as follows. The maximum strain value appears at the central rib, followed by the transverse strain value of the bottom plate, and the minimum strain value is the longitudinal strain of the bottom plate. The deformation of the rib is the largest, while the longitudinal deformation is always greater than the transverse deformation. Simulation of the crack development trend in the loading process can help obtain a more intuitive understanding of the load transfer path in the U-UHPFRC structure.

(5) Based on the crack propagation theory of damage mechanics, the component crack development state and failure modes in the test are analyzed. The possible ductile failure modes under the concentrated load are given. The theoretically calculated value of the ultimate bending capacity is $146.34 \mathrm{kN}$, and it is higher than the actual test value of $138.39 \mathrm{kN}$ by only $5.4 \%$. Thus, the established theoretical bearing capacity calculation model is safer than the actual test model. Therefore, the presented theoretical calculation model can accurately determine the bearing capacity and provide a reference for UHPFRC bridge engineering design and analysis.

\section{Data Availability}

The data used to support the findings of this study are available from the corresponding author upon request.

\section{Conflicts of Interest}

The authors declare that there are no conflicts of interest regarding the publication of this paper.

\section{Acknowledgments}

The authors would like to acknowledge CSC (no. 201406560024) and the technical support that was received from the staff of the Laboratory of Maintenance and Safety of Structures (MCS-ENAC). This work was financially supported by the Natural Science Foundation of Shandong Province (nos. ZR2019PEE017 and ZR2020QE260) and Doctoral Research Foundation of Linyi University (no. 40618071).

\section{References}

[1] A. A. Semendary and D. Svecova, "Factors affecting bond between precast concrete and cast in place ultra high performance concrete (UHPC)," Engineering Structures, vol. 216, Article ID 110746, 2020.

[2] J.-H. Sun, "Application of ultra high performance concrete in newly built ground bridges," Value Engineering, vol. 26, no. 37, pp. 173-174, 2018.

[3] J. Xue, B. Briseghella, F. Huang et al., "Review of ultra-high performance concrete and its application in bridge engineering," Construction and Building Materials, vol. 260, Article ID 119844, 2020. 
[4] E. Bruehwiler, "Bridge "examineering" or how monitoring and UHPFRC improve the performance of structures," Bridge Maintenance Safety Management \& Life Extension, Infoscience-EPFL, Lausanne, Switzerland, 2014.

[5] M. A. Treacy and E. Brühwiler, "A direct monitoring approach for the fatigue safety verification of construction joint details in an existing post-tensioned concrete box-girder bridge," Engineering Structures, vol. 22, no. 3, pp. 180-186, 2015.

[6] A. D. Reitsema, M. Lukovi'c, S. Grünewald et al., "Future infrastructural replacement through the smart bridge concept," Materials, vol. 13, no. 405, pp. 1-14, 2020.

[7] E. Brühwiler and E. Denarié, "Rehabilitation and strengthening of concrete structures using ultra-high performance fibre reinforced concrete," Structural Engineering International, vol. 23, no. 4, pp. 450-457, 2013.

[8] I. Z. Bribián, "Life cycle assessment of building materials: comparative analysis of energy and environmental impacts and evaluation of the eco-efficiency improvement potential," Fuel \& Energy Abstracts, vol. 46, no. 5, pp. 1133-1140, 2011.

[9] C. Oesterlee, "Structural response of reinforced UHPFRC and RC composite members," Doctoral thesis, 4848, École polytechnique fédérale de Lausanne (EPFL), Lausanne, Switzerland, 2010.

[10] E. Brühwiler, "Structural UHPFRC" to enhance bridges," in Proceedings of the 2nd International Conference on UHPC Materials and Structures. China Fuzhou: (UHPC 2018-China), pp. 140-158, Fuzhou, China, November 2018.

[11] P. Ranjan Prem, B. H. Bharatkumar, and N. R. Iyer, "Mechanical properties of ultra high performance concrete," World Academy of Science Engineering \& Technology, vol. 29, no. 10, pp. 1647-1653, 2012.

[12] B. Rabehia, Y. Ghernoutia, A. Lib et al., "Comparative behavior under compression of concrete columns repaired by fiber reinforced polymer (FRP) jacketing and ultra highperformance fiber reinforced concrete (UHPFRC)," Journal of Adhesion Science \& Technology, vol. 28, no. 23, pp. 2327-2346, 2014.

[13] R. Yu, P. Spiesz, and H. J. H. Brouwers, "Static properties and impact resistance of a green ultra-high performance hybrid fibre reinforced concrete (UHPHFRC): experiments and modeling," Construction and Building Materials, vol. 68, no. 15, pp. 158-171, 2014.

[14] J.-S. Zhua, Y.-G. Wanga, J.-B. Yana et al., "Shear behaviour of steel-UHPC composite beams in waffle bridge deck," Composite Structures, vol. 234, no. 22, Article ID 111678, 2020.

[15] A. M. Sharif, N. A. Assi, and Al-Osta, "Use of UHPC slab for continuous composite steel-concrete girders," Steel and Composite Structures, vol. 34, pp. 321-332, 2020.

[16] K. Deng, M. T. Wang, and K. C. Wang Zhao, "Numerical study on a fully-prefabricated damage-tolerant beam to column connection for an earthquake-resilient frame," Engineering Structures, vol. 159, pp. 320-331, 2018.

[17] V. Pribramsky and M. Kopálová, "Application of precast UHPC web members for long-span bridge structures," Solid State Phenomena, vol. 259, pp. 140-145, 2017.

[18] S. Gurusideswar, A. Shukla, K. N. Jonnalagadda et al., "Tensile strength and failure of ultra-high performance concrete (UHPC) composition over a wide range of strain rates," Construction and Building Materials, vol. 258, Article ID 119642, 2020.

[19] L. Fan, W. Meng, L. Teng et al., "Effects of lightweight sand and steel fiber contents on the corrosion performance of steel rebar embedded in UHPC," Construction and Building Materials, vol. 238, no. 30, Article ID 117720, 2019.

[20] Z. Wang, J. Wang, G. Zhao et al., "Design criterion for the self-centering capacity of precast segmental UHPC bridge columns with unbonded post-tensioning tendons," Engineering Structures, vol. 200, Article ID 109706, 2019.

[21] X. Shen and E. Brühwiler, "Biaxial flexural fatigue behavior of strain-hardening UHPFRC thin slab elements," International Journal of Fatigue, vol. 138, Article ID 105727, 2020.

[22] X. Shen, E. Brühwiler, and P. Wang, "Biaxial flexural response of Strain-Hardening UHPFRC circular slab elements," Construction and Building Materials, vol. 255, Article ID 119344, 2020.

[23] X. Shen and E. Brühwiler, "Influence of local fiber distribution on tensile behavior of strain hardening UHPFRC using NDT and DIC," Cement and Concrete Research, vol. 132, Article ID 106042, 2020.

[24] Y. Hu, Z. M. Meloni, and H. J. XiuWang, "Flexural performance of steel-UHPC composite beams with shear pockets," Structures, vol. 27, pp. 570-582, 2020.

[25] J. Wei, J. Li, and C. Wu, "An experimental and numerical study of reinforced conventional concrete and ultra-high performance concrete columns under lateral impact loads," Engineering Structures, vol. 201, Article ID 109822, 2019.

[26] J. Liu, Z. Chen, D. Guan et al., "Experimental study on interfacial shear behaviour between ultra-high performance concrete and normal strength concrete in precast composite members," Construction and Building Materials, vol. 261, Article ID 120008, 2020.

[27] F. Baby, P. Marchand, and F. Toutlemonde, "Shear behavior of ultrahigh performance fiber-reinforced concrete beams. II: analysis and design provisions," Journal of Structural Engineering, vol. 140, no. 5, pp. 472-482, 2014.

[28] T. Noshiravani and E. Brühwiler, "Experimental investigation on reinforced ultra-high-performance fiber-reinforced concrete composite beams subjected to combined bending and shear," ACI Structural Journal, vol. 110, no. 2, pp. 251-261, 2013.

[29] K. Wille and A. E. Naaman, "Pullout behavior of high-strength steel fibers embedded in ultra-high-performance concrete," ACI Materials Journal, vol. 109, no. 4, pp. 479-488, 2012.

[30] E. Brühwiler and E. Denarié, "Rehabilitation of concrete structures using ultra-high performance fibre reinforced concrete," in Proceedings of the the Second International Symposium on Ultra High Performance Concrete (UHPC), Kassel, Germany, March 2008.

[31] K. Habel, E. Denarié, and E. Brühwiler, "Structural response of elements combining ultrahigh-performance fiber-reinforced concretes and reinforced concrete," Journal of Structural Engineering, vol. 132, no. 11, pp. 1793-1800, 2006.

[32] T. Makita and E. Brühwiler, "Damage models for UHPFRC and R-UHPFRC tensile fatigue behaviour," Engineering Structures, vol. 90, pp. 61-70, 2015.

[33] D. Nicolaides and G. Markou, "Modelling the flexural behaviour of fibre reinforced concrete beams with FEM," Engineering Structures, vol. 99, pp. 653-665, 2015.

[34] S. Rigaud, G. Chanvillard, and J. Chen, "Characterization of bending and tensile behaviors of ultra-high performance concrete containing glass fibers," Proceedings of High Performance Fiber Reinforced Cement Composites, vol. 6, pp. 359-366, 2011. 
[35] W. H. Mosley, J. H. Bungey, and R. Hulse, Reinforced Concrete Design: To Eurocode 2, Palgrave Macmillan, London, UK, 2012.

[36] NAFNOR, P18-710: National Addition to Eurocode 2-Design of Concrete Structures: Specific Rules for Ultra-high Performance Fiber-Reinforced Concrete (UHPFRC), Association Française de Normalisation, Rue Francis de Pressensé, France, 2016.

[37] National Standard of the People's Republic of China, Code for Design of Highway Reinforced Concrete and Prestressed Concrete Bridges and Culverts JTG D60-2018, Beijing: People's Communications Press, 2018.

[38] SIA (Swiss Society of Engineers and Archtitects), Technical Leaflet SIA 2052 UHPFRC-Materials, Design and Construction, SIA (Swiss Society of Engineers and Archtitects), Zurich, Switzerland, 2016. 